\title{
Monopólio estético e diversidade configuracional no futebol brasileiro
}

Arlei Sander Damo*

Resumo: este artigo tem por objetivo criticar o monopólio temático exercido pelo futebol profissional. Para tornar este argumento mais claro serão apresentados quatro modelos configuracionais em torno dos quais a diversidade futebolística é melhor visualizada e compreendida: o futebol profissional (de espetáculo ou de alto rendimento), o futebol de bricolagem (futebol de improviso, informal, pelada, racha, etc.), o futebol comunitário (futebol de várzea, amador, de bairro, de fábrica, etc.) e o futebol escolar (institucional, disciplinar, etc.). A parte final do texto está direcionada para o futebol comunitário, com a finalidade de dar visibilidade acadêmica a um dos segmentos que a narrativa hegemônica encobriu, mas que revela-se de grande interesse às ciências sociais e, quero crer, à Educação Física.

Palavras-chave: Cultura, Esporte, Futebol, Diversidade.

\section{Brasil, país dos "futebóis"}

As ciências sociais brasileiras resistiram, até a década de 1980, a abordagem das práticas corporais em geral e dos esportes em particular. Gradativamente, porém, a resistência foi afrouxada, seguindo uma tendência observada em outros países, como na França e na Inglaterra, por exemplo. Prova disso é que a Associação Brasileira de Antropologia ( $\mathrm{ABA}$ ) e a Associação Nacional de Pós-Graduação e Pesquisa em Ciências Socias (ANPOCS), pressionadas pela sistematicidade das pesquisas em curso na última década, abriram espaço para o novo objeto em seus eventos científicos - a ABA em 2000 e a ANPOCS em 2002. As trocas entre os pesquisadores até então isolados se intensificaram, consolidando os debates, a regularidade das investigações e das

* Professor do Departamento de Ciências Humanas da Universidade de Santa Cruz do Sul, doutorando em Antropologia Social pela Universidade Federal do Rio Grande do Sul e atualmente em estágio de bolsa sanduíche junto ao Institut d'Ethnologie Méditerranéenne et Comparative (Aix-en-Provence/France).

Movimento, Porto Alegre, v. 9, n. 2, p. 129-156, maio/agosto de 2003 
publicações. A crítica, inerente à prática acadêmica, revela que, apesar de notáveis avanços, a recente produção tem dificuldade de estabelecer uma ruptura em relação ao olhar midiático, especialmente em relação ao jornalismo e à crônica esportiva.

Um dos impulsos decisivos para a mudança de perspectiva em relação ao rótulo de que o futebol seria um ópio do povo, pelo menos no Brasil e na América Latina, ocorreu com a publicação de uma coletânea organizada por Roberto DaMatta (1982). Entre a coletânea um texto do próprio DaMatta - Esporte na sociedade: um ensaio sobre o futebol brasileiro - exerceria forte influência nos anos seguintes. Neste texto o autor afirma ter o futebol brasileiro as características de um evento dramático no qual o jogo não é senão a roupagem que encobre e ao mesmo tempo adorna uma complexa trama de significados. ${ }^{1}$ Os embates entre as equipes que representam nações ou clubes dramatizariam os sentimentos de identidade e de pertencimento não apenas daqueles que efetivamente estão em campo, mas sobretudo dos que participam do drama desde as arquibancadas ou mesmo através das mídias. Nos rituais dramáticos, caracterizados por um estado de ânimo alterado e, portanto, diverso do cotidiano, seriam expressos determinados sentimentos que não poderiam ser conveniente e convincentemente manifestos em outras esferas da vida social.

O mais importante da contribuição damattiana talvez seja a inclusão do futebol no conjunto dos fatos sociais relevantes ao entendimento da sociedade brasileira. DaMatta reiterou em relação a este esporte a tese principal de Carnavais, Malandros e Heróis (1979), segundo a qual se compreende melhor o Brasil e o que pensam sobre ele os brasileiros quando nos afastamos das instituições ditas sérias - como o Estado e o mercado, por exemplo - e observamos alguns fatos sociais aparentemente menos cotados. Em resumo, perde-se em compreensão do Brasil e dos brasileiros quando se deixa de lado a música, o carnaval, as religiões, o jogo do bicho e o futebol.

A partir deste impulso muitos trabalhos foram realizados e em razão do alargamento dos horizontes interpretativos é possível, duas décadas depois, retomar criticamente os escritos

1 DaMatta é influenciado, nesta interpretação, pela Escola de Manchester - cf. Kuper (1978) - e, particularmente, pelas análises de Turner (1974a, 1974b) sobre os processos rituais.

Movimento Porto Alegre, v. 09, n. 2, p. 129-156, maio/agosto de 2003 
damattianos. Uma destas críticas diz respeito ao tratamento homogêneo conferido ao futebol. Quem lê DaMatta procurando saber a qual referente empírico ele está se dirigindo quando usa o termo futebol, não terá dificuldade em identificar na versão espetacularizada ou profissionalizada este referente. A crítica talvez se aplique menos a DaMatta, um pioneiro, e mais adequadamente aos trabalhos que se seguiram a ele. ${ }^{2}$

Embora contribuindo para tornar o futebol digno de ser investigado, DaMatta limitou-se à interpretação de um fato social colado àquele pressuposto pelas narrativas midiáticas. Os trabalhos que se seguiram, quase todos citando DaMatta, reproduziram-se na mesma perspectiva estética. Para se ter uma idéia acerca da hegemonia temática do profissionalismo basta consultar o artigo de Toledo (2001), no qual é feito um balanço acerca do estado da arte em termos de investigações e publicações, entre 1980 e 2001, tendo o futebol como tema nas ciências sociais brasileiras. O rastreamento desta bibliografia, a mais completa já realizada, aponta a existência de aproximadamente uma centena de trabalhos, entre teses, dissertações, artigos, livros, resenhas e outras formas de divulgação científica. Dentre esta centena há pelo menos uma dezena de teses e uma quantidade duas vezes maior de dissertações, nas áreas de antropologia, história social, sociologia, ciência política, psicologia, letras, geografia, economia, filosofia e comunicação. ${ }^{3}$

Surpreendentemente - ou não -, apenas duas entre uma centena de publicações referidas por Toledo são direcionadas ao futebol de várzea e uma única às peladas. Prevalece, pelo que se pode depreender dos títulos em geral e da leitura integral de boa parte destes trabalhos, o tratamento genérico dado ao futebol, como se não houvesse uma diversidade de formas de praticálo e vivenciá-lo para além do viés profissional. Equivocadamente, este que é apenas um dos segmentos acabou por ser pulverizado. Ao menos em parte, reproduz-se, na escolha dos temas acadêmicos, a lógica do establishment midiático. ${ }^{4}$

2 Outra discordância em relação os diversos escritos damattianos refere-se à particularização ou abrasileiramento de certos aspectos transnacionais do futebol profissional ou, na direção inversa, ao abrasileiramento e generalização de certos localismos regionais. Para uma crítica mais detida da interpretação damattiana do futebol cf. Damo (2002a).

3 Por razões desconhecidas não foram inclusos os trabalhos realizados no campo da EFI, à exceção de uma ou outra contribuição.

4 Sobre a relação entre a crônica e o jornalismo esportivo e a produção acadêmica no campo das ciências socias, cf. Lovisolo (2001).

Movimento, Porto Alegre, v. 9, n. 2, p. 129-156, maio/agosto de 2003 
Se o interesse seletivo da grande mídia é compreensível desde o ponto de vista da audiência - e, por extensão, dos contratos publicitários valorados pelas leis de mercado -, o recorte acadêmico é questionável. Afinal, não se está dando importância demasiada ao segmento profissional do futebol em detrimento da diversidade do fato social? Não estariam as ciências sociais deixando-se pautar pela grande mídia, ela própria um segmento integrante do futebol profissional? ${ }^{5}$ Boa parte dos trabalhos referidos por Toledo não estariam influenciados por uma visão de senso comum não esclarecido, colada ao simbolismo dos próprios pesquisadores, de tal modo que o interesse acadêmico reproduziria a inserção pessoal destes agentes no universo futebolístico, notadamente como torcedores? 6

O tratamento exaustivo destas questões não pode ser realizado aqui, mas elas servem como pano de fundo e justificativa para a demonstração de que há futebol fora das narrativas hegemônicas. É preciso fazê-lo aparecer, com seus personagens, suas memórias, narrativas, dilemas, paixões, enfim, urge flanar pelos campos de futebol da nação, sobretudo pelos campos que, por razões diversas, não se enquadram nos padrões da Internacional Board. A ampliação dos horizontes analíticos pode contribuir, inclusive, para a releitura da produção referida por Toledo (2001). Quiçá a diversidade não esteja encoberta pelas cinzas que, uma vez sopradas, farão aparecer o braseiro?

\section{A diversidade configuracional do futebol brasileiro}

A unidade nominal, escreveu Bourdieu (1990), “(...) mascara uma dispersão, mais ou menos forte, conforme os esportes, das maneiras de praticá-los" (:209-10) e isto dificulta a análise. Para compreender as lógicas daquilo que se apresenta como nominalmente uno, as ciências sociais dispõem de ferramentas e a antropologia, particularmente, desenvolveu um conjunto de métodos e técnicas normalmente abrigadas sob o termo etnografia. Todavia, há circunstâncias em que mesmo a etnografia enfrenta dificuldades, especialmente quando defrontada com

5 Para uma arguição mais detalhada acerca da intersecção entre mídia esportiva e esporte profissional/espetáculo, razão pela qual ambos devem ser tratados simultaneamente, evitando-se atribuir à mídia a visão distanciada que por vezes reivindica - sobretudo os cronistas, comentaristas e historiadores enganjados - cf. Leite Lopes (1994) e Toledo (2002).

6 Estes questionamentos podem ser considerados também em relação à produção acadêmica no campo da EFI, embora eu desconheça, até o presente, um mapeamento nos moldes realizados por Toledo (2001).

Movimento Porto Alegre, v. 09, n. 2, p. 129-156, maio/agosto de 2003 
os desafios inerentes à extensão e pluralidade de espaços sociais e estilos de vida nas/das cidades. ${ }^{7}$ Nestes casos em que a diversidade cria embaraços, não há como esquivar-se do uso de certos dispositivos metodológicos como os que se seguem.

Todos os conceitos são formas de classificação e de reordenação para além das classificações de primeiro grau, realizadas por agentes concretos em contextos igualmente situados no tempo e no espaço. A compreensão - ou mesmo a explicação - da sociedade e da cultura desde o ponto de vista das ciências sociais pretende-se mais abrangente, densa e diversa daquela que possuem os agentes concretos. As interpretações em segundo ou terceiro grau, como arranjos constituídos a partir de arranjos pré-existentes, não devem, contudo, ignorar jamais seu ponto de partida - que para muitos também deve ser o ponto de chegada. Nesta perspectiva, urge encontrar possibilidades intermediárias ao empirismo ingênuo, atachado às narrativas dos agentes sociais, e ao idealismo subversivo, que simplesmente ignora a dimensão vivida do social e do simbólico.

As noções de campo, de configuração e de tipo-ideal - identificadas com Bourdieu, Elias e Weber, respectivamente - são parte destas possibilidades intermediárias ao empirismo e ao idealismo, pois transcendem os fatos concretos sem contudo mutilálos. O uso de um destes conceitos e, sobretudo, o uso de um arranjo produzido a partir deles, talvez demande mais cautela do que aquela que estou tendo, mas sendo este um texto dirigido a um público supostamente alheio às minúcias e querelas conceituais próprias das ciências sociais, reservo-me a liberdade de proceder através de atalhos, apresentando o produto de uma discussão realizada alhures. Em outras palavras, vou direto ao arranjo final das categorias campo, configuração e tipo-ideal.

A noção de campo, importada de Bourdieu, ${ }^{8}$ serve como guia de leitura, de revisão de literatura e, sobretudo, como uma bús-

7 Aqueles que se interessam pelas discussões em torno da pertinência, relevância e alcance da etnografia nas cidades (ou das cidades) podem conferir a recente contribuição de Magnani (2002) sobre o tema.

8 As diferentes conceituações de campo encontradas em Bourdieu podem ser condensadas em duas direções principais: a) como "(...) uma estenografia conceitual de um modo de construção do objeto que vai comandar - ou orientar - todas as opções práticas da pesquisa (...), como um sinal que lembra o que há de fazer, a saber, verificar que o objeto em questão não está isolado de um conjunto de relações de que retira o essencial das suas propriedades" (Bourdieu, 1989:27); e b) como "espaço social de relações objetivas" (:64), um ponto de partida para a compreensão das estratégias empreendidas pelos agentes na produção e reprodução social.

Movimento, Porto Alegre, v. 9, n. 2, p. 129-156, maio/agosto de 2003 
sola que, se não diz exatamente o caminho a ser trilhado pela exegese, ao menos oferece indícios de fronteiras, trilhas convencionais e/ou inexploradas, encruzilhadas e assim por diante. Este conceito ajuda a compreender a floresta estando no meio dela, sem se perder. Trata-se não apenas de um ponto de partida, mas também de um pressuposto imanente ao método: há um todo (campo) no interior do qual - e tão somente sob tal condição - as partes (agentes) são o que são; pensam, criam, oferecem resistência, produzem/reproduzem, etc. O agente, seja ele pesquisador ou pesquisado, é produto e produtor do (campo) social.

Se esta noção de campo nos permite recortar, para depois recompor, o futebol do esporte e este do conjunto ampliado das práticas corporais, também possibilita estabelecer fronteiras na diversidade futebolística. Seriam os subcampos, talvez. Todavia, a esta altura creio que a ferramenta mais indicada seja a noção de figuração ou de configuração desenvolvida por Elias. ${ }^{9}$ Esta noção também pode prestar-se ao uso metodológico - como guia, bússola, etc. -, mas serve particularmente para demarcar uma certa rede de relações empiricamente constituída, com sujeitos concretos situados no espaço e no tempo. É a partir dela que Elias (2001) descreve a "sociedade de corte" ou, no sentido inverso e complementar, é estudando as cortes européias que ele arquiteta o conceito de configuração.

Nesta linha de raciocínio, as peladas - mais adiante denominadas de futebol de bricolagem - são configurações, não apenas porque têm uma dimensão empírica, mas porque o peladeiro do Parque Ramiro Souto pode jogar nas peladas do Parque Marinha do Brasil - ambos em Porto Alegre - e também nas peladas do Complexe Sportif Val d'Arc - em Aix-en-Provence -, tal qual um nobre ou cortesão poderia circular entre as cortes européias dos séculos XVII e XVIII, na medida em que dominasse os códigos, as regras de etiqueta, enfim, o habitus. Mas como um plebeu excluí-

9 Na perspectiva de Elias a sociedade está nas interações e não há interações sem sujeitos individuais. A investigação das interações ou interdependências é realizada por meio de observações empíricas e a partir delas pode-se "(...) determinar o surgimento e o desenvolvimento de figurações específicas - no caso os de uma corte real e de uma sociedade de corte - com alto grau de precisão, embora não de maneira exaustiva. Podemos estabelecer que condições tornaram os homens interdependentes numa dada situação, e como essas interdependências se modificam sob o efeito das alterações, tanto endógenas como exógenas, da figuração em seu conjunto." (Elias, 2001:214). 
do da corte, um peladeiro encontrará resistência para jogar no Flamengo, por exemplo. Ocorre que o Flamengo não está para as peladas como uma corte está para outra, mas como uma corte, qualquer que seja, está para o plebeu em geral. Logo, o Flamengo e as peladas do Parque Ramiro Souto pertencem a configurações distintas, embora conexas. ${ }^{10}$

O peladeiro do Parque Ramiro Souto não é simplesmente alguém que escolheu uma prática corporal para ocupar seu tempo de lazer, senão que sua escolha recaiu sobre uma prática esportiva e, particularmente, sobre o futebol - o caminho inverso também é possível de ser pensado e seria mais coerrente com a lógica do concreto. Todavia, seu interesse pelo futebol pode leválo a um estádio, mas na condição de torcedor, o que implica que a transição de uma configuração a outra pode demandar a mudança do papel - de jogador para torcedor - e, por extensão, dos constrangimentos, das redes de relações e dos significados da ação.

As noções de campo e de configuração são faces distintas da mesma moeda. A chave bourdiana nos permite acessar os constrangimentos aos quais um indivíduo está sujeito por participar de um grupo, aos sistemas de significados que ele incorpora na e pela prática aparentemente gratuita de uma pelada, por exemplo. A chave eliasiana opera melhor no sentido inverso, possibilitando compreender a ação dos indivíduos no grupo, as estratégias particulares e mesmo as brechas que tornam possíveis as expressões idiossincráticas - ser identificado por um apelido, como tendo um estilo de jogo, um temperamento próprio, etc.

É justamente para diferenciar a noção de configuração empírica de uma noção mais alargada que necessito introduzir a noção de tipo-ideal. Dos três conceitos citados anteriormente, certamente este é aquele mais descolado do universo empírico ou, por outra, é o mais arbitrário, pois trata-se de uma ferramenta do pesquisador. O emprego dos termos tipo-ideal ou puro, tal qual Weber (1979) o fez para definir os "três tipos de dominação" um texto clássico em termos de metodologia -, implica que o pes-

10 Não se justificaria, pelo tanto que já se produziu em discursos sobre o futebol, que alguém retorne do Parque Ramiro com uma conclusão desta ordem - e tão pouco contrária a ela -, mas antes que ele fosse ao Parque sabendo que a configuração empírica - os sujeitos concretos e suas relações dentro e fora do espaço-tempo do jogo - que ele observará está conectada a outras configurações, mesmo que os tais "sujeitos concretos" não se percebam assim.

Movimento, Porto Alegre, v. 9, n. 2, p. 129-156, maio/agosto de 2003 
quisador deva estar consciente, de antemão, de que não encontrará uma correspondência precisa entre a definição conceitual (ideal, pura, formal, etc.) e os fatos concretos.

Por economia de linguagem usarei, daqui por diante, apenas o termo configuração, mas ele pressupõe os esclarecimentos feitos nos parágrafos precedentes. Por configurações futebolísticas compreendo as segmentações possíveis de um universo amplo e diversificado cujo termo futebol unifica. As quatro segmentações ou matrizes são conexas umas às outras, mas cada qual possui sua especificidade. O que permite distingui-las não é propriamente o significado atribuído à prática, mas o espaço, o tempo e a morfologia social (composição do público, redes específicas de relações e interesses, divisão social do trabalho dentro e fora do espaço-tempo de jogo e conexões diversas para além do futebol, do esporte e das práticas corporais).

A diversidade futebolística pode, então, ser agrupada nas configurações denominadas de: futebol profissional, também referido por alguns autores como futebol-espetáculo ou futebol de alto rendimento/performance; futebol de bricolagem, conhecido como fute, pelada, baba, racha e outras designações locais; futebol comunitário, em certos contextos nomeado de futebol de várzea e em outros como futebol de bairro ou amador; e o futebol escolar, vinculado à instituição escolar desde o século XIX, como dispositivo pedagógico de uso alargado e transformado em conteúdo da EFI ao longo do século XX.11

Estas quatro matrizes configuracionais são uma alternativa a outras formas de classificação do futebol - e dos esportes em geral -, dentre as quais aquela que estabelece a dicotomização entre o amadorismo e o profissionalismo. O uso do par amador/ profissional - ou qualquer de seus derivativos gramaticais - pelos próprios agentes, em seus contextos de trabalho ou lazer, impregnou-os com juízos de valor (Damo, 2002b). Por vezes o par é usado para separar aqueles que recebem salários e têm no esporte seu meio de subsistência daqueles que têm em relação ao esporte um apego supostamente desinteressado, de quem

\footnotetext{
11 Se esta caracterização é extensiva ao esporte como um todo é outra questão. Ela não foi pensada para tal e muito provavelmente teria que passar por adaptações. De outra parte, não descartaria de antemão esta possibilidade. Outras variantes de futebol, como o futsal, o futebol sete, suíço, de areia, etc, podem, tranqüilamente, encaixar-se nas respectivas configurações. No Brasil, o futsal talvez seja o único que se distribui em todas as quatro configurações.
} 
faz por amor. Em outros casos, porém, o termo profissional é identificado com predicados do mundo do trabalho e dos negócios, tais como competência, seriedade, esforço, dedicação e bom desempenho, entre outros. O termo amador, em contra-partida, associa-se àquele que faz sem esperar recompensa ou simplesmente faz de qualquer jeito, sem o empenho, a disciplina e a performance do universo das coisas sérias.

Já o uso acadêmico do par amadorismo/profissionalismo serve - pelos menos tem sido usado com tal intenção - para demarcar duas realidades tidas como distintas, sendo o segundo termo decorrente de transformações no próprio futebol, fundado e inicialmente disseminado sob a égide do amadorismo. O que separaria estes dois segmentos seria, sobretudo, a remuneração, mas em certos casos se acrescenta a legislação trabalhista e em outros a exigência de alta performance.

Como não se pode impedir ou disciplinar o uso social da linguagem, o que resta ao campo acadêmico é encontrar outras possibilidades para que possa, a partir delas, descolar-se da interpretação de primeira ordem, aquela realizada pelos sujeitos ou grupos concretos. De que valem os termos amadorismo e profissionalismo para se compreender as peladas, por exemplo? Trata-se de uma prática amadora, sem dúvida, mas o que mais poderia ser dito a respeito delas? De outra parte, é dificil separar o par interesse/desinteresse desde o ponto de vista simbólico, sendo mais prudente pressupor um funcionamento dialético, razão pela qual não se deve associar arbitrariamente amadorismo com desinteresse - o amador é um desinteressado em relação a quê?

A ampliação do leque de categorias, tendo por base as configurações anteriormente mencionadas, não pretende instituir uma nova classificação para os fatos sociais, rivalizando com outras tantas classificações sugeridas por autores diversos. O objetivo é, sobretudo, circunscrever para melhor compreender. Desde o ponto de vista empírico ou mesmo das representações sociais, as fronteiras entre as configurações sugeridas nem sempre são tão nítidas quanto aqui destacadas pois, como dito anteriormente, tratam-se de categorias analíticas de tipo-ideal, ainda que pensadas a partir de fatos concretos. Também sugere-se que elas sejam pensadas na forma de configurações conexas. Ou seja, as diferentes manifestações do futebol podem ser vistas como histórica, social e culturalmente aparentadas. Este parentesco

Movimento, Porto Alegre, v. 9, n. 2, p. 129-156, maio/agosto de 2003 
seria dado por uma espécie de átomo futebolístico, ${ }^{12}$ forma residual/estrutural partilhada por todas as matrizes, em razão da qual, muito provavelmente, as nomenclaturas locais - pelada, baba, football de pied d'immeuble, etc. - são traduzíveis e compreensíveis como futebol. ${ }^{13}$

\section{O futebol profissional ${ }^{14}$}

O futebol profissional caracteriza-se por um conjunto de particularidades dentre as quais três delas se destacam. A mais importante, talvez, seja a forma monopolista, globalizada e hierarquicamente organizada através da Federation Internationale de Football Association (FIFA). A FIFA e suas afiliadas - as confederações e abaixo delas as federações nacionais e, em países como o Brasil, estaduais - organizam eventos (campeonatos, torneios, copas, etc.), estabelecem normas para as relações entre os clubes e controlam a circulação dos atletas e de boa parte do comércio das imagens, as principais fontes de receita deste futebol.

12 O átomo futebolístico, que nada tem a ver com o conceito físico-químico desta partícula, é uma analogia à noção de átomo de parentesco, uma definição lévistruassiana usada para se referir às relações elementares e universais do parentesco (1949). O que interessa reter aqui é a idéia de que existe um núcleo, composto de certos atributos a partir dos quais o futebol, em que pese suas variações, seja definido como tal. Assim, teríamos que o "átomo futebolístico" seria composto por: a) duas equipes (princípio de coletividade); b) com objetivos ou metas contrários (princípio do conflito); c) sendo a disputa mediada por um objeto (princípio da evitação do contato corpo-a-corpo); d) que não pode ser tocado com as mãos, salvo excessões (uma interdição criada para diferenciar o football do rugby); e) e um conjunto de regras (circunscrevendo o espaço, o tempo e o ilícito).

13 O "atomo futebolístico", deriva, em última instância, do football assotiation, nome dado ao código redigido e aprovado em 1863, em Londres, por alunos de várias universidades inglesas visando padronizar as regras das diferentes modalidades de football por eles praticado. A padronização das regras era uma imposição à realização de intercâmbios e mostrou-se decisiva para o processo de popularização deste football (Murray, 2000-19-41).

14 Alguns autores da área do treinamento esportivo denominam esta modalidade de futebol como "esporte de alto rendimento" ou de "alta performance". Por um lado, a discussão de nomenclaturas me parece secundária, mas por outro, deste ponto de vista da apreensão do futebol enquanto fenômeno sociocultural, é preciso transcender os termos "alto", "baixo", "médio", etc, pois eles tendem a arrastar as distinções para os quesitos técnicos e sobretudo para os mensuráveis. A diversidade narrativa, que respeita a contribuição das diferentes disciplinas acadêmicas, é preferível em relação à totalização ou condensação forçada. A visão de conjunto, certamente desejável, é mais facilmente alcançada pela pluralidade de recortes. Enfim, não é problema que as ciências interpretativas recortem o esporte e as práticas corporais de forma diversa daquela presente no jornalismo ou na EFI. Antes de pretender o monopólio legítimo das definições sobre as práticas corporais, oferta-se uma contribuição pretensamente distanciada, na medida em que as ciências sociais não têm em relação ao tema a mesma relação - direta, criadora/reprodutora, etc. - que possui a pedagogia. 
O profissionalismo também se caracteriza pela intensa divisão social do trabalho. Não obstante a distinção clara e precisa entre quem pratica e quem assiste (torcedores/espectadores/consumidores), há neste meio uma expressiva rede de outras especialidades e estas podem ser segmentadas de acordo com certos princípios classificatórios em torno dos quais produzem-se as diferenças, as similitudes e as lutas em relação às competências, aos interesses e às reciprocidades. Com a ressalva de que faltou dar aos dirigentes um destaque diferenciado e de que seu o modelo aplica-se ao futebol profissional - mas não abarca a diversidade do fato social - concordo com a caracterização apresentada por Toledo (2002).

a) Os profissionais [diretos]; "todos aqueles que interferem diretamente no jogo, quer dentro do campo, como a própria performance dos jogadores, técnicos ou juízes na busca imediata dos resultados, quer na percepção dos jogadores, fisiologistas, preparadores físicos, etc., ou no suporte administrativo dos dirigentes (...) que viabilizam a competição como espetáculo (Toledo, 2002:16).

b) Os especialistas; “(...) [os] que procuram decodificar e ordenar para uma narrativa supostamente mais linear e universalista, a partir das técnicas disponíveis de cada meio midiático, o processo ritualístico em evento jornalístico, de interesse geral (:17)";

c) Os torcedores; aqueles que impõem ao futebol "a circularidade das emoções" (:17), importando-se sobretudo com a capitalização simbólica do desfecho dos rituais agonísticos.

A divisão social do trabalho, constitutiva da profissionalização e espetacularização, distingue este futebol das outras configurações. A excelência performática, por seu turno, é uma exigência mediada pelos interesses do público, tal qual se observa em configurações ligados ao "mundo das artes". ${ }^{15}$ As exigências do público acarretam a dedicação exclusiva de quase todos os profissionais diretos - e não apenas dos atletas. Em contrapartida, a dedicação integral é remunerada como trabalho. Dos atletas exige-se preparação específica para os eventos (jogos) e a especialização em relação ao uso das técnicas corporais, individuais

15 Sobre o uso sociológico do termo "mundo das artes" cf. Becker (1988).

Movimento, Porto Alegre, v. 9, n. 2, p. 129-156, maio/agosto de 2003 
e coletivas, condição indispensável para que elas sejam exibidas ao público. A exibição na forma de um confronto estilizado e espetacularizado faz do jogo um rito agnóstico. Este rito, que tende à separação entre vencedores e perdedores, é fundamental para a produção e circulação das emoções antes, durante e depois do espaço-tempo do jogo propriamente dito.

Como em outras modalidades artísticas ou esportivas, o gosto do público e os interesses da indústria do espetáculo classificam alguns artistas como dignos de compensação e outros como muito dignos, de dinheiro e de outras dádivas. No caso dos esportes, parte da beleza do espetáculo parece indissociada do limite ao qual a competitividade foi sendo guindada, sendo esta liminaridade - condição daquilo que está na fronteira - seguidamente dramatizada, como no caso do controle/descontrole emocional. Em razão disso, nem toda a prática de futebol é considerada como interessante (ou absorvente) pelo público - caso das peladas, por exemplo, mas também de muitos jogos do circuito profissional.

\section{O futebol de bricolagem}

Esta é a configuração que admite as mais diversas possibilidades de adaptações em relação às normas da Internacional Board - comitê que detém o monopólio legítimo sobre as regras do football association, oficialmente adotado pela FIFA -, desde que mantido o "átomo futebolístico" anteriormente mencionado. Se considerarmos que estas adaptações são ilimitadas e observadas em quase todos os contextos socioculturais nos quais o futebol é praticado, poder-se-ia denominá-lo de improviso. Mas o termo bricolagem me parece mais condizente, pois a noção de improviso sugere a idéia de carência e impropriedade. Uma pelada não é incompleta porque só há três jogadores para cada equipe ou porque jogam descalços. Pelo contrário, é esta bricolagem que caracteriza as peladas: joga-se com o que se dispõem ou então inventa-se, quer sejam as regras ou os recursos materiais. O que caracteriza esta configuração futebolística é a sujeição do football association aos contornos locais, ao espaço, tempo, material, enfim, aos contornos físicos, psíquicos e sociais dos praticantes.

De maneira geral o tempo da bricolagem é o tempo social do não-trabalho - do lazer, da recreação, do ócio, etc. -, ainda que seus praticantes possam se empenhar de modo tão laborioso, com intenso desperdício de energia física e psíquica, que por vezes a atividade parece ser uma extensão ou até potencialização do trabalho. A duração do jogo varia de acordo com a disposição dos praticantes - condicionamento atlético, excitação individual e

Movimento Porto Alegre, v. 09, n. 2, p. 129-156, maio/agosto de 2003 
coletiva, entre outros -, com a disponibilidade de tempo para tal atividade ou em função de outros fatores externos, como as condições climáticas, acessibilidade e limitação do tempo imposta pela locação dos espaços para a prática. ${ }^{16}$

A divisão social do trabalho, intensa, estruturada e em processo de complexificação crescente no futebol profissional é praticamente inexistente nas peladas. Especialmente quando circunscrevemos a observação à divisão social das tarefas desempenhadas pelos jogadores no interior do jogo, observa-se uma precária distinção entre atacantes e defensores, ou quando esta distinção existe é fruto de arranjos situacionais, ao contrário do que ocorre com os profissionais que se especializam não apenas no aprimoramento das técnicas corporais voltadas para o futebol, senão que na execução de tarefas tão particulares como a cobrança de um escanteio pelo lado direito.

Todavia, além das diferenças estéticas decorrentes do aprimoramento e do uso utilitário - ou não - das técnicas corporais, explícitas na comparação entre peladeiros e profissionais; da relativização da performance e da ausência de espectadores nas peladas; dos arranjos e recriações do football association; entre outras questões, a bricolagem está ligada à construção da masculinidade. A exceção de alguns grupos restritos para os quais a formação do self masculino prescinde do uso direto do corpo, a bricolagem futebolística é importante na formação e demonstração de uma imagem pública de menino e não parece menos necessária para que os homens propiciem, a eles mesmos, um raro espetáculo de hostilidade e afeto.

Em outros contextos, como o europeu, por exemplo, o rugby é tido como o esporte masculino por excelência (Saouter, 2000), mas no Brasil é no futebol que os machos - de quase todas as idades - constituem sua masculinidade. Não é apenas através do futebol que um menino se faz homem, mas não gostar de futebol ou não ser um bom praticante - por vezes estas aptidões estão associadas - cria certos constrangimentos. O preconceito em relação às mulheres que jogam futebol - e mesmo o uso que fazem dele alguns grupos de lésbicas -, a pressão exercida sobre os meninos pelos próprios meninos, a exclusão e hostilidade em relação à participação das meninas, além das metáforas, analogias e outros tantos artifícios do poder simbólico expresso na linguagem - poder de divisão, hierarquização e significação do

16 Sobre os arranjos em termos de regras, redes de relações sociais e significados atribuídos à sociabilidade futebolística, cf. a etnografia de Stigger (2002).

Movimento, Porto Alegre, v. 9, n. 2, p. 129-156, maio/agosto de 2003 
mundo, como diria Bourdieu - dão uma idéia do quanto o futebol é importante na construção de gênero no Brasil.

Há no esporte, no futebol e na bricolagem um fértil terreno à investigação das questões envolvendo o masculino e o feminino. A capacidade de criar, arranjar e estruturar diferenças faz do futebol um lugar onde a maquinaria simbólica opera em ritmo alucinante. Mais do que naturalizar as diferenças, o futebol apresenta-se, ele mesmo, como função naturalizante, quer dizer, a simples prática deste esporte impregna o sujeito de certos atributos tidos como naturais. Mais do que criticar a exclusão das mulheres - mas jamais do feminino! - ou a naturalização das diferenças de gênero, mas não apenas elas, urge compreender as razões pelas quais o futebol ocupa, no Brasil e em muitos outros países, um lugar destacado, de um operador prático e simbólico de diversas modalidades de identidades sociais.

O futebol de bricolagem constitui um campo ainda inexplorado, não apenas às ciências sociais, mas também às pedagogias que pretendem, além de intervir, compreender os meandros do processo de ensino e aprendizagem. Na bricolagem não se ensina ou não se aprende apenas uma prática - do futebol, neste caso -, mas um espectro de códigos, valores e normas denominados de cultura. É preciso ter cuidado, pois a cultura, como afirma Sahlins (1997), é um arranjo, mas raramente coerente. A própria noção de bricolagem futebolística dá uma idéia do que se pode encontrar quando se invade a trama configuracional destes eventos discretos, quase invisíveis aos nossos olhos, tal é a nossa familiaridade.

\section{O futebol comunitário}

Entre o profissinal e o bricoleur existe ao menos uma modalidade de futebol, vinculada ao tempo de lazer dos seus praticantes, realizada em espaços mais padronizados do que a bricolagem, mas sem a ortodoxia dos campos oficiais e tampouco circunscritos a uma edificação que dá ao espaço uma conotação sagrada - caso dos estádios, por exemplo. Talvez o que melhor caracterize este futebol intermediário - em boa parte do Brasil, ao menos de São Paulo em direção ao Sul é chamado de futebol de várzea - é a presença de quase todos os componentes do futebol profissional, porém diferindo em escala.

Em alguns casos as federações estaduais - conectadas à estrutura da FIFA - organizam eventos que congregam a elite destes clubes, mas prevalece, sobretudo, a organização de competições em circuitos locais - bairros, cidades, dependendo das circunstâncias. A divisão social do trabalho fora de campo não é

Movimento Porto Alegre, v. 09, n. 2, p. 129-156, maio/agosto de 2003 
nula, mas precária. Todos os times de várzea têm um técnico e quase todos têm também um dirigente e um massagista. Diferente da bricolagem, portanto. Mas o técnico de várzea não é remunerado e nem treina a equipe durante a semana. No jogo os papéis são, por princípio, bem definidos e até especializados, mas não deve causar surpresa se o centroavante, a certa altura, for jogar de goleiro; ou se o senhor grisalho, que estava com a sete e fora substituído ainda antes do intervalo, reaparecer como beque de espera nos minutos finais da partida.

A grande mídia, de alcance nacional e estadual, simplesmente ignora a existência do futebol comunitário ou notabilizao por meio de seus subprodutos - confusões, improvisos, bebedeiras e comilanças, etc. Vez por outra aparece uma nota, quase sempre por benevolência pessoal do jornalista. Nas cidades de menor porte, no entanto, o semanário publica a tabela, o regulamento e a classificação do certame, geralmente chamado de municipal ou regional. Por asseptismo a várzea vira amador e a cada rodada a rádio local transmite um derby, sendo os patrocinadores da jornada esportiva pequenos empreendedores locais, não raro o poder público; e se eles concedem patrocínio é graças à interferência pessoal do locutor ou do dono da rádio.

O futebol comunitário tende a se organizar em forma de associações clubísticas e estas a constituição de associações mais amplas denominadas de ligas. Estas últimas, entretanto, raramente excedem um bairro, vila ou cidade de pequeno porte, uma espécie de circuito fechado ou reduzido, muito distante do que a FIFA representa. ${ }^{17}$ Há entre estas associações algumas com

17 No caso da Europa Ocidental, sobretudo da França, onde a presença do Estado é abrangente e a prática esportiva institucionalizada é regulamenta desde o final dos anos de 1960, este futebol intermediário está integrado ao sistema federativo, de modo que é possivel, a partir da FIFA, chegar a um pequeno clube de bairro de qualquer cidade francesa. Por intermédio de sucessivas subdivisões, o A. AM.S. Val Sant'Andre - clube de futebol do quartier de mesmo nome, de Aix-en-Provence - integra a base de uma pirâmide na qual o Olimpique de Marseille, da cidade distante trinta quilômetros, está no topo. Este modelo holístico, hierarquizado e vigiado pelo Estado não é, entretanto, o mesmo existente no Brasil, no qual a organização do futebol - mesmo e sobretudo do profissional - é matizada pela cultura local. Se tentarmos percorrer a estrutura da FIFA em direção ao Brasil, chegaremos, numa cidade como Porto Alegre, no máximo aos clubes da segunda divisão estadual, mas jamais ao Academia do Morro, da Vila Maria da Conceição, ou ao Banguzinho, da Bom Jesus - campeão e vice do Municipal de Várzea 2002. Tampouco chegaremos aos lendários Dínamo e Clarão da Lua; nem aos outros quase 300 clubes de futebol comunitário da cidade (dados da Secretaria Municipal de Esportes). Esta nota dá uma idéia do que seja a extensão da configuração comunitária no Brasil, mas não toca, nem de leve, na diversidade de personagens, formas de organização e de significados. Em contrapartida, revela-nos que o mundo, camarada, não é propriamente do tamanho de "uma antena parabólica".

Movimento, Porto Alegre, v. 9, n. 2, p. 129-156, maio/agosto de 2003 
longa trajetória, assim como existem atletas renomados. Enfim, entrar e sair deste circuito não demanda o mesmo capital corporal do profissionalismo, mas também não é tão poroso quanto o futebol de bricolagem.

\section{O futebol escolar}

Finalmente, um quarto segmento configuracional, cuja importância tem sido igualmente esquecida pelos pesquisadores em ciências sociais. Trata-se do futebol praticado nas escolas, integrado aos conteúdos da EFI, como parte das disciplinas legalmente constituídas. Além de ser um conteúdo ou um dispositivo pedagógico das aulas de EFI, há muitos colégios - como os de orientação jesuítica e luterana - que incentivam a organização de festivais, de competições intramuros ou em rede. Desde o ponto de vista do uso das técnicas corporais e até mesmo do seu estatuto simbólico, este futebol não possui uma diferença expressiva em relação às outras configurações, especialmente quando prevalece a pedagogia do laisser-faire. A tendência, nestes casos, é de que o futebol escolar assuma as configurações da bricolagem.

Alguns autores, como Tubino (1992), incluiriam esta configuração no rol do educacional.18 Desde o ponto de vista das ciências sociais, no entanto, a classificação de Tubino é embaraçosa pois a ação educativa - em sentido aberto, implicando as relações de ensino e aprendizagem - não acontece em um espaço único e tampouco numa instituição (a Escola, para os ocidentais), assim como não há um tempo ou uma intencionalidade homogêneos. Aprende-se e ensina-se futebol de formas diversas, de modo que toda a prática e mesmo a contemplação esportiva poderiam ser consideradas atos educativos - das técnicas corporais, da sensibilidade estética, do controle/descontrole emocional, etc. Educativo tenderia a ser antes de tudo um juízo local, ligado ao ponto de vista dos atores sociais e, portanto, relacionado ao significado da ação - da prática do futebol, por exemplo. Em resumo, educativo pode vir a ser um dos predicados do futebol escolar, mas certamente não é o único e talvez não seja sequer o principal.

18 As classificações de Tubino foram mais tarde incorporadas à chamada Lei Zico e mantida na Lei n 9.615 - popularmente conhecida como Lei Pelé -, no Capítulo III, "DA NATUREZA E DAS FINALIDADES DO DESPORTO". "Art. 3o O desporto pode ser reconhecido em qualquer das seguintes manifestações: I - desporto educacional, praticado nos sistemas de ensino e em formas assistemáticas de educação, evitando-se a seletividade (...); II - desporto de participação, de modo voluntário (...); III - desporto de rendimento, praticado segundo normas gerais desta Lei e regras de prática desportiva (...)". A lei já não é responsabilidade de Tubino, mas dá uma idéia de quão aberto é este tipo de definição denominado de "educacional". (Grifos meus). 
A diferença desta configuração em relação às demais é, obviamente, a instituição escolar, ela mesma passível de variações em termos de significado e função de acordo com diferentes contextos históricos. A sociogênese dos esportes modernos não deixa dúvidas quanto à importância da escola, de alunos e exalunos, dos grêmios estudantis, enfim, de uma rede extensa de atores e instituições que esportivizaram os jogos pré-modernos. ${ }^{19}$

Mesmo assim a literatura brasileira em ciências sociais praticamente ignora este segmento, à exceção de uma ou outra referência periférica acerca da importância de algumas instituições tradicionais - como o Colégio Rio Branco, no Rio de Janeiro, ou o Mackenzi, em São Paulo - na disseminação do ethos esportivo no princípio do século. Certamente que a invisibilidade da instituição escolar é produto da hipertrofia do futebol profissional, como já referido anteriormente, reforçado pela crença de que as instituições formais não têm muita importância no ensino e na aprendizagem das técnicas corporais, sobretudo do chamado futebol-arte, ao contrário do domínio aberto da rua.

19 Tanto na produção brasileira quanto européia em ciências sociais, os esportes denominados de modernos - por diferenciaçao às práticas pré-modernas ou inventadas às margens da idéia de civilização européia - são tidos como produtos e produtores da "modernidade". O "ponto zero", a partir do qual a diáspora esportiva teve início, na segunda metade do século XIX, são as Public Schoo/s inglesas e em menor intensidade os colégios jesuítas. A fixação desta origem é certamente tendenciosa, mas incontestável quando se pretende marcar uma posição acadêmica que valoriza as genealogias ou contextos de surgimento ao invés das origens - nomes, datas, etc. Esta perspectiva tem o mérito de acabar com as especulações em torno do "protofutebol" e, sobretudo, de uma pespectiva positivista, ainda observada em algumas publicações que tendem a traçar uma continuidade absurda desde os "tempos da Grécia, de Roma...aos nossos dias". A este respeito bem vale lembrar João Saldanha, frasista inveterado, para quem o futebol tivera origem no princípio do mundo - isto explicaria sua popularidade, inclusive -, quando Adão, ao desfazer-se do fruto proibido, teria usado os pés. Como o mito bíblico é omisso em relação a maneira como Adão livrou-se da maçã, a conjectura de Saldanha é possível e dá bem a idéia de onde se pode chegar quando se tem fixação "pelas" origens. Outra coisa, muito diferente, é especular ou mesmo historicizar a existência de práticas estruturalmente e por vezes esteticamente próximas àquelas popularizadas pelos ingleses. Não apenas os gregos e os romanos, mas também os astecas, os maori e outras sociedades não ocidentais são objeto de interesse. Certos rituais agonísticos, que os etnógrafos relataram e vincularam quase sempre à magia, à religião, ao parentesco e mesmo ao mercado, devem ser revisitados. Eles constituem uma espécie de horizonte a partir do qual se pode pensar comparativamente, fazendo aparecer as diferenças e, por extensão, as "nossas" singularidades. São bons enquanto possibilidades de alargamento conceitual e isto nada tem a ver com a construção artificial de continuidades, quer sejam estruturais ou conjecturais.

Movimento, Porto Alegre, v. 9, n. 2, p. 129-156, maio/agosto de 2003 
De outra parte, no quadro da divisão social da pesquisa, a escola e tudo o que dela se aproxima, provavelmente esteja entregue aos pesquisadores ligados às áreas pedagógicas - à EFI, por exemplo. Neste caso o futebol escolar estaria sendo problematizado juntamente com outros esportes, especialmente no processo de reflexão enunciado pela EFI visando repensar o tecnicismo, a reprodução das distinções de gênero e a competitividade excessiva, entre outros.

Em relação a esta última perspectiva vale dizer que a diluição do futebol no rol das modalidades esportivas e estas no conjunto dos dispositivos usados pela EFI é acertada desde o ponto de vista da tradição da própria disciplina e não menos pertinente se considerarmos que a compreensão de uma dada prática esportiva haverá de ser tanto mais refinada quando pensada a partir do ponto de vista relacional (Bourdieu, 1990). Todavia, não se pode jamais negligenciar a importância diferenciada, desde o ponto de vista da densidade simbólica, de algumas modalidades. No caso brasileiro, o futebol - independente de suas configurações - está impregnado por um conjunto de significações, parcialmente estruturadas pela tradição.

A EFI, enquanto uma disciplina pedagógica e, portanto, constituída para e pela intervenção, para e por um olhar de perto e de dentro, não apenas de onde as coisas acontecem, mas acontecendo junto com elas, pode oferecer resistência ou então reproduzir os simbolismos associados ao futebol. A escolha é complexa, de cunho político, e cabe aos pedagogos discutir as implicações de uma ou outra possibilidade - ou de intermediários, negociados ou não com os alunos. A contribuição das ciências sociais é um tanto modesta neste aspecto e, qualquer que seja o rumo do debate na EFI, o que de melhor se pode fazer é emprestar uma interpretação acerca do objeto em questão. ${ }^{20}$

\footnotetext{
20 Francamente não me considero em condições de avaliar os "progressos" da EFI em relação às questões de gênero e tampouco em relação a outros temas manifestamente controversos, como é o caso da valorização/desvalorização/hipervalorização do ensino das técnicas esportivas, da excelência performática, da disciplina, entre outros. A historia da EFI, escrita e debatida por profissionais da área - por pedagogos que "conhecem a aldeia" - é prova de que a disciplina, no seu conjunto, busca tomar consciência de si. Todavia, o resgate do passado, por si só, não explica o presente, não protege o futuro e nem alarga os horizontes do debate. Isto não é uma crítica aos historiadores da EFI - tenho um olhar de sobrevôo e a producão me parece heterodoxa, com bons e nem tão bons trabalhos, compreensível para uma especialidade em formação, tal qual a produção em ciências sociais sobre o esporte - mas uma sinalização, talvez desnecessária, de que outras disciplinas têm muito a contribuir no debate. Mas há também os modismos e eles fluem com impressionante velocidade, nas asas dos "estudos culturais", por exemplo.
} 
Finalmente, há de ser observado que a escola, ou certos dispositivos forjados por e através dela, estão migrando para o interior dos clubes esportivos e para as escolinhas de futebol. É interessante notar que nestes espaços, especialmente nas escolinhas, não apenas se ensinam e se aprendem as técnicas futebolísticas, mas acreditam os meninos, seus pais e sobretudo os professores - ex-atletas ou licenciados em EFI - ser este processo singular: disciplinado, formador do caráter, metódico, criterioso e assim por diante. Trata-se de uma migração de valores, profissionais, disciplinas, enfim, de mentalidades. Mas isto não implica que a assimilação seja generalizada ou que os fluxos não enfrentem resistência.

A segmentação do conjunto das práticas nominalmente referidas como futebol, cindidas e/ou agrupadas em quatro configurações distintas - futebol profissional (de espetáculo ou de alto rendimento), futebol de bricolagem (futebol de improviso, informal, pelada, racha, etc.), futebol comunitário (futebol de várzea, amador, de bairro, de fábrica, etc.) e futebol escolar (institucional, disciplinar, etc.) - requer ainda muita pesquisa de campo. Não custa ressaltar, mais uma vez, que o objetivo destas matrizes não é a construção de modelos no qual os dados empíricos sejam encaixados, mas a tentativa de compreender a diversidade com mais profundidade, com certas fronteiras, ainda que porosas e freqüentemente transgredidas, que vão do espaço físico à cultura.

\section{Breves cenas, cenários e personagens do futebol comunitário}

Graças ao capital econômico e social de seus freqüentadores, boa parte dos clubes de elite do futebol profissional (que outrora foram da elite e continuam sendo política e administrativamente controlados por ela - ou por elas, desde que se compreenda por elite um grupo heterodoxo de homens tidos, por eles próprios, como bem-sucedidos social e economicamente) dispõem de registros da sua trajetória, escritos nos jornais de grande circulação e sobretudo nas publicações internas. A várzea carece de homens/mulheres - mas sobretudo homens, uma vez que são eles quem dominam também a várzea - letrados para registrar sua memória e, para ser franco, seu público talvez nem se importe muito com isso. Seja como for, a história social do futebol

Movimento, Porto Alegre, v. 9, n. 2, p. 129-156, maio/agosto de 2003 
de várzea ou seu presente e, por extensão, sua visibilidade, dependem do interesse acadêmico. Há, sim, personagens, instituições e estilos de sociabilidade varzeanos com os quais se pode aprender através da pesquisa; há, sim, "outros" no futebol. ${ }^{21}$ Para fechar este artigo, cujo objetivo principal é sensibilizar o leitor para uma ruptura em relação à hegemonia estética do futebol profissional, retratarei dois episódios ou cenas especialmente ligados à configuração comunitária do futebol portoalegrense. É importe trazer a público estes recortes etnográficos na medida em que eles não apenas contribuem para retratar melhor o que entendo por futebol comunitário, mas também apresentar a maneira como a etnografia pode contribuir neste empreendimento, com um flash - dois, no máximo - de uma configuração concreta, não mais de tipo-ideal.

Os campos comunitários estão em toda a parte do território brasileiro: alguns são de propriedade do Estado, outros são cedidos por agentes privados, boa parte são adquisições de associações comunitárias e, finalmente, há os baldios, terrenos à mercê da especulação imobiliária e, portanto, condenados. Desde os grandes conglomerados urbanos até os lugarejos pouco povoados, há invariavelmente um espaço, mais ou menos preservado, destinado a esta configuração.

Para dar conta das razões pelas quais alguns destes campos de futebol são preservados, formulam-se teses das mais diversas matizes, desde aquelas vinculando a pobreza à ignorância e, por vezes, à irracionalidade - pois onde já se viu privilegiar o futebol ao invés da moradia? - até às que sugerem hipóteses

21 Seguindo-se as caracterizações expressas aqui, pode-se identificar, aqui e ali referências mais ou menos extensas ao futebol comunitário e a seu público. Magnan e Morgado (1996) são autores de um artigo retratando o processo de tombamento do Parque do Povo, em São Paulo, no qual é enfatizada a importância dos campos de futebol de várzea enquanto espaços de sociabilidade dos grupos populares. Antunes (1994 e 1996) publicou partes de sua dissertação de mestrado sobre o futebol nas fábricas, uma configuração próxima do futebol de várzea. Também Pereira (2000) dedica parte da sua narrativa acerca da história social do futebol no Rio de Janeiro, 1903-1938, aos clubes de menor expressão, situados no subúrbio carioca. Escrevendo sobre a Liga dos Canelas Pretas, uma associação de clubes formados por negros e mulatos, excluídos da elite do futebol porto-alegrense - da qual faziam parte o Grêmio e o Internacional -, Mascarenhas (1998) e Damo (2002c:86120) resgatam não mais do que fragmentos da sociabilidade futebolística nos circuitos "menos cotados" do futebol. Guedes (1997) mantém o futebol próximo ou refere-se diretamente a ele quando analisa o processo de construção social da identidade de um grupo de trabalhadores urbanos de classes populares. No ano seguinte (Guedes 1998:81-136) retorna ao futebol de periferia, mostrando a sua importância em vários momentos da vida dos homens de grupos populares, sejam eles meninos, jovens ou adultos, correspondendo às diferentes etapas da vida social, distintas formas de apropriação desta prática. 
menos preconceituosas. Dentre estas últimas sobressai a idéia de que tais espaços aparentemente vazios transcendem o futebol, sendo importantes para a sociabilidade das comunidades do entorno. Qualquer que seja a interpretação acerca das razões pelas quais os campos de várzea são preservados, elas necessitam ao menos satisfazer uma condição de verossimilhança: partir do pressuposto de que eles não representam uma contradição em relação ao uso racional do espaço físico, mesmo quando este é escasso. À preservação destes espaços físicos corresponde a reprodução de um espaço social vinculado às práticas coletivas, das quais o futebol é uma das mais importantes.

Nos campos comunitários são realizados jogos com times de fora, de outros pedaços - para seguir um conceito de Magnani (retomado a seguir) - e como tal são uma porta de entrada para pessoas de outras vilas, bairros, cidades, de pessoas de outras comunidades. São também espaços de lazer e recreação das crianças e adolescentes, do chimarrão e das fofocas, da circulação de animais domésticos, enfim, os campos são espaços multiuso. Abrir a possibilidade de que um único barraco seja edificado sobre o campo seria consentir com a conversão do campo em pequenos lotes até fazê-lo desaparecer, sem contudo solucionar o problema da habitação precária.

A diversão e o consumo são realizados coletivamente, na interação face-a-face com outros indivíduos. O lazer no entorno ou dentro do campo comunitário está a meio caminho entre a casa e a rua - ou entre o privado e o público, se preferirem - não propriamente aberto à presença de qualquer cidadão, mas igualmente distante da sociabilidade privada, seja ela realizada em espaço aberto ou fechado. Os valores individualistas, mais identificados com o estilo de sociabilidade das camadas altas, parecem avessos a esta configuração futebolística. Joga-se, bebe-se, come-se, discute-se e por vezes briga-se, mas raramente só ou em pequenos grupos. O time pode ser controlado pelo traficante da zona, mas as pessoas de bem não são excluídas e quando tem jogo em outros pedaços, seguem com a excursão mais pessoas do que o time e a rede do trafi.

Romantizar este futebol é a última coisa que se pretende aqui, razão pela qual o parágrafo precedente não deve ser lido como elogioso ou saudosista. No universo heteróclito dos grupos populares, os quais as ciências sociais têm dificuldade de

Movimento, Porto Alegre, v. 9, n. 2, p. 129-156, maio/agosto de 2003 
conceituar, 22 prevalece o gosto pela sociabilidade coletiva. Tratase de uma característica destes grupos, especialmente quando comparados às camadas médias ou altas. O gosto pela sociabilidade mais aberta e coletiva é, ao menos em parte, resultado de estratégias bem sucedidas de reprodução de códigos, valores e atitudes destes grupos, como no caso do Seu Manoel, retratado a seguir.

Muito diferente do bairro Petrópolis, onde situa-se o campo do Parque Tamandaré, ou do bairro Moinhos de Vento, que contém o campo do Parcão, é a situação da Vila Maria da Conceição, nos altos do Partenon, também conhecida por Maria Degolada - a contragosto dos moradores locais, óbvio. Atémeados dos anos oitenta não havia um único local destinado à prática de esportes na Maria da Conceição, enquanto os campos do Tamandaré e do Parcão raramente eram usados pela comunidade do entorno, pois olazer das classes altas segue uma tendência generalizada de realizar-se nos clubes, um espaço preservado e seletivo, para parceiros de status equiparado.

Então surgiu uma possibilidade para o pessoal da Conceição: um terreno de aproximadamente 600 metros quadrados, situado na parte alta do morro, com uma bela vista da cidade, onde outrora montavam-se os circos - depois deles veio uma escola improvisada e mais tarde um depósito de material de construção do Município. Quando o depósito foi desativado a comunidade fez com que o terreno se transformasse num pequeno campo de futebol. Mas o terreno era de propriedade particular e a qualquer momento, quando o mercado imobiliário julgasse pertinente, poderia ser dada outra destinação.

Seu Manoel, um senhor de 81 anos, 48 de Maria da Conceição, decidiu-se à luta para que o poder público adquirisse aquela área. E não era apenas isso: quis manter o "campinho de futebol da gurizada".

Em dezembro de 2001, numa manhã de domingo, Seu Manoel foi anfitrião do prefeito e de outras autoridades municipais que participaram do cerimonial de "posse do terreno". Seu Manoel estava muito orgulhoso por ter sido um dos batalhadores para a conquista daquele espaço, uma luta que começara em 1992. A boa vontade do poder público não fora suficiente para que a negociação tivesse o êxito e a rapidez desejados. Foi preciso permutar o terreno com os proprietários e isto demorou mais do que o imaginado, com vários imprevistos no decorrer do processo. A insistência, com incontáveis audiências e peregrinações pela burocracia, exigiu muito esforço de Seu Manoel, como exigiria de qualquer trabalhador que além do seu sustento estivesse envolvido com os "problemas" da comunidade.

22 De qualquer modo popular não é sinônimo de pobre (Magnani e Morgado, 1996:182), mas uma designação que abarca um extenso contingente de grupos que freqüentemente se denominam como tal. Eles se reconhecem não apenas pela condição de privação em relação ao consumo de determinados bens, mas sobretudo por partilharem certos códigos éticos e estéticos que os afirmam enquanto homens e mulheres trabalhadores, respeitáveis, com familia, devotos e assim por diante. 
Para o dia da inauguração, Da Tabela ${ }^{23}$ organizou um pequeno torneio entre equipes de crianças e adolescentes da Vila. A SME deslocou o ônibus Brincalhão, estacionado numa rua lateral, abaixo do nível do campo. Parte dos brinquedos não puderam ser usados por falta de espaço, tendo a cama elástica permanecido (mal fixada) numa das bordas do Vermelhão.

A certa altura a brincadeira foi interrompida para as falas do prefeito e demais autoridades, entre as quais seu Manoel. Em seu depoimento ele contou a história de como havia sido a luta para conquistar aquele espaço, sendo que de tempos em tempos havia uma pausa seguida de um olhar em direção ao prefeito è̀s demais lideranças locais que balançavam afirmativamente a cabeça. Ao final, mencionou os planos para incrementar o local e a importância que ele teria para as crianças do morro.

Tempos depois o vermelhão recebeu o tão sonhado telamento (alambrado), adquirindo uma nova "presença". O mais importante, segundo Seu Manoel, é que agora ele está seguro de que aquela comunidade tem espaço para o "divertimento". Ele sabe o quanto estes espaços são importantes na Vila e isto que ele nem liga para o futebol, orgulhando-se, assanhado, de nunca ter posto os pés no estádio do Grêmio e tampouco do Internacional. (Descrição construída a partir de vários diários de campo, desde a inauguração do Vermelhão (dezembro de 2001), visita ao local durante a realização do telamento e bate-papo/entrevista com Seu Manoel (julho/agosto de 2002)).

Ainda que a historiografia tradicional da classe trabalhadora nem sempre tenha dado a importância devida ao que se passava fora do espaço-tempo das fábricas ou da militança sindical e/ou partidária, percebe-se, aqui e ali, certo interesse pela sociabilidade e pelo lazer dos grupos populares. Em Festa no Pedaço, uma etnografia pioneira tematizando o lazer e o entretenimento dos grupos populares, Magnani (1998) trata sucintamente do futebol de várzea, da sua importância enquanto gerador de eventos no pedaço ou como mecanismo que possibilita o intercâmbio com outras comunidades. Quase duas décadas depois, a etnografia de Magnani mantém-se atualizada, mesmo porque nota-se entre os grupos populares um empenho na preservação de certas práticas de sociabilidade e, por extensão, de identidade social.

O Parque Tamandaré, localizado em bairro de classe média, média-alta, não está entre os mais conhecidos da cidade. Em torno do parque nota-se as mudanças graduais que estão transformando parte do bairro. O Tamandaré está localizado próximo à Av. Protásio Alves, uma das mais importantes da cidade, mais ou menos à altura onde outrora localizava-se o final da linha dos bondes. Periferia

23 Dizem ser o apelido invulgar, obra de um gaiato da Vila que notou no sujeito uma verdadeira obsessão por converter toda e qualquer atividade lúdica, do pingpong à peteca, em competição. Com tabela, evidentemente!

Movimento, Porto Alegre, v. 9, n. 2, p. 129-156, maio/agosto de 2003 
nos anos 40 e 50, o entorno do Tamandaré está em permanente mutação. Antigos casarões dão lugar a edifícios, residenciais ou comerciais, bem mais requintados do que as antigas habitações.

o Tamandaré não é muito extenso, mas bem arborizado. Uma parte do parque éocupada peloplayground e pelos bancos postados sob as árvores cinqüentenárias; outra parte abriga os equipamentos esportivos: um campo de dimensões restritas, mas com alambrado; duas quadras poliesportivas de cimento; um módulo que serve como sede da associação dos amigos do parque, sala de reuniões, vestiário e almoxarifado.

Até bem pouco tempo o Tamandaré era freqüentado pela comunidade do entorno, usuária principal dos equipamentos esportivos. A partir de 1998, entretanto, o Parque adquiriu um público de outros pedaços. Através da demanda junto ao Orçamento Participativo, o campo de futebol foi iluminado, de forma que passaram a ser disputados jogos à noite. Os refletores permitiram a realização de campeonatos e em pouco tempo moradores de comunidades carentes deáreas de lazer tomaram conhecimento de que o Tamandaré é um Parque da cidade, pertencente a todos os porto-alegrenses e não apenas aos moradores do entorno.

Opessoal da Vila Conceição, localizada nos altos do Partenon chega ao parque com o ônibus T2; os da Vila Bom Jesus podem servir-se de várias linhas que circulam pela Protásio Alves e há quem venha da Vila Jardim e de outras vilas e/ou bairros de fácil acesso. Alguns moradores estranham a movimentação intensa, especialmente aos finais de semana. Os mais preconceituosos sugerem que a prefeitura deveria construir campos de futebol na vila, para o pessoal de lá ficar lá.

Sem que nada disso tivesse sido planejado, embora desejado por parte da atual gestão da cidade, moradores de determinados núcleos urbanos adquirem mobilidade no tempo de lazer. O bairro Petrópolis era apenas um bairro de passagem ou local de trabalho para moradores da Bom Jesus, Conceição e Vila Jardim faxineiras, operários da construção civil, porteiros, etc. Agora é um lugar de lazer. As fronteiras da nova identidade do parque são demarcadas com futebol, pagode, churrasquinho, algumas brigas e crianças tresloucadas pelo playground; enfim, o Tamandaré não é mais o mesmo. O bairro que se elitiza arquitetonicamente, se populariza esportivamente. Há sempre quem prefira ver a cidade em fragmentos, com seus guetos de pobreza e de riqueza, se possível bem distantes, de modo que as contradições desapareçam. Mas há quem pense em sentido contrário... (Notas etnográficas escritas a partir de várias incursões ao Tamandaré, como assessor do Coordenador do Setor de Futebol da Secretaria Municipal de esportes)

Alguns teóricos, como Richard Sennet, por exemplo, argumentam que as formas de sociabilidade pública estão em processo de extinção no ocidente. A sociedade em que vivemos está sobrecarregada de conseqüências dessa história: o evanescimento da res pública pela crença de que as significações sociais são geradas pelos sentimentos de seres humanos individuais (1988:413). Em lugar do público teria emergido o culto ao privado e ao privativo, ao indivi-

Movimento Porto Alegre, v. 09, n. 2, p. 129-156, maio/agosto de 2003 
dualismo e, por extensão, à fragmentação do social. Mas não em toda a parte! Um dos pontos frágeis deste discurso de Sennet é a falta de percepção acerca de certas transformações em relação ao tipo de atividade realizada em público, à generalização excessiva e a não relativização das próprias categorias de público e privado. Os esportes coletivos em geral e o futebol em especial, sobretudo em países como o Brasil em que ele é densamente vivenciado, servem para repensar este discurso generalista em relação ao englobamento do privado pelo público. A reprodução da configuração comunitária de futebol sugere, nesta mesma linha de raciocínio, que a lógica individualista e privatista encontra gradientes de aceitação variáveis de acordo com determinados espaços, tempos e culturas.

Talvez o leitor tenha estranhado que este artigo, como reiteradas críticas à produção recente das ciências sociais sobre o futebol, esteja publicado por um periódico de circulação na esfera da EFI. Boa parte destas críticas aqui enunciadas já foram veiculadas em outras publicações ou comunicações, na ABA e na ANPOCS, de maneira que não se trata de fugir do debate têteà-tête, por quaisquer que sejam os motivos. Para ser franco, boa parte do que foi dito, em pretenso demérito, cabe às minhas próprias publicações, também elas à mercê de um quebra-cabeça que só recentemente começa a ser montado. Como consolo pode-se dizer que a montagem segue a passos largos. Como a EFI tem se aproximado das ciências sociais em busca de referenciais teóricos e metodológicos, algumas críticas precisam ser socializadas para evitar a reedição de equívocos.

Espero, ao menos, convencê-los de que o fato social futebolístico (talvez esportivo) tem muitas faces desconhecidas e elas têm muito a nos dizer. Mas a diversidade, a fragmentação e a heterodoxia, características das culturas e sociedades concretas, e não propriamente das ciências interpretativas, precisam ser de algum modo domesticadas. Não basta dizer que há fluxos de informações, pessoas, saberes, significados ou seja lá o que for. É preciso identificar as direções, seus agentes, as circunstâncias, enfim, é com esta finalidade que pensei à demarcação das fronteiras das quatro configurações aqui apresentadas. Elas foram pensadas a partir das variáveis tempo, espaço, morfologia, divisão social do trabalho, entre outras. Os sentidos que as configurações concretas atribuem ao futebol e as modalidades de interações que protagonizam faz parte da etapa seguinte, muito mais complexa e desafiadora. As configurações de tipo-ideal são um ponto de partida; não mais do que isto.

Movimento, Porto Alegre, v. 9, n. 2, p. 129-156, maio/agosto de 2003 
Monopolio estético y diversidad de configuraciones en el fútbol brasileño

Resumen: el artículo tiene por objetivo criticar el monopolio temático ejercido por el fútbol profesional. Para hacer más clara esta argumentación serán presentados cuatro modelos de configuración donde la diversidad futbolística puede ser mejor visualizada y comprendida: el fútbol profesional (de espectáculo o de alto rendimiento), el fútbol de bricolaje (fútbol de improvisación, informal, etc.), el fútbol comunitario (fútbol amador, de barrio, de fábrica, etc.) y el fútbol escolar (institucional, disciplinar, etc.). La parte final del texto está dirigida al fútbol comunitario, con la finalidad de dar visibilidad académica para uno de los segmentos que la narrativa hegemónica ha encubierto, pero que es de gran interés para las Ciencias Sociales y para la Educación Física.

Palabras claves: Cultura, Deporte, Fútbol, Diversidad.

\section{Esthetic monopoly and configurational diversity in Brazilian soccer}

Abstract: this article has as objective to criticize the thematic monopoly exerted by professional soccer. To make this argument clearer there will be presented four configurational models around which the soccer diversity is better understood and viewed: the professional soccer (spectacle or high profit), the bricolage soccer (improvisation and informal soccer, etc.), the communitarian soccer (amateur, corporative, etc.) and the school soccer (institutional, instructed, etc.). The final part of the text is directed to the "communitarian soccer", and with the purpose to give academic visibility to one of the segments hidden by the hegemonic narrative, but revealed as a great interest to the social sciences and, I believe, to the Physical Education.

Keywords: Culture, Sport, Soccer, Diversity.

\section{Referências}

ANTUNES, Fátima (1994). O futebol nas fábricas. In: Revista USP, nº 22.

ANTUNES, Fátima (1996). O futebol na Light \& Power de São Paulo. In: Pesquisa de Campo, n 3-4, p. 51-64.

Movimento Porto Alegre, v. 09, n. 2, p. 129-156, maio/agosto de 2003 
BECKER, Howard (1988). Les Mondes de l'Art. Paris: Flammarion.

BOURDIEU, Pierre (1989). O poder simbólico. Rio de Janeiro:Bertrand Brasil. BOURDIEU, Pierre (1990). Programa para uma sociologia do esporte. In: Coisas Ditas. São Paulo, Brasiliense.

DAMATTA, Roberto (1979). Carnavais, malandros e heróis: para uma sociologia do dilema brasileiro. Rio de Janeiro.

DAMATTA, Roberto (1982). Universo do futebol: esporte e sociedade brasileira. Rio de Janeiro, Pinakotheke.

DAMO, Arlei Sander (2002a). Do ópio do povo à antropologia do óbvio: leitura crítica dos escritos de Roberto DaMatta sobre futebol. Comunicação no Fórum Antropologia do Esporte, 23a Reunião da ABA, Gramado/RS, 16-19 de junho de 2002.

DAMO, Arlei Sander (2000b). O uso dos termos amadorismo e profissionalismo como categorias sociológicas na literatura acadêmica sobre o futebol. Comunicação apresentada no GT Esporte, Política e Cultura, XXVI Reunião Anual da Anpocs.

DAMO, Arlei Sander (2002c), Futebol e identidade social: uma leitura antropológica da rivalidade entre torcedores e clubes. Porto Alegre, Editora da UFRGS.

ELIAS, Norbert (2001). A sociedade de corte: investigação sobre a sociologia da realeza e da aristocracia de corte. Rio de Janeiro: Zahar.

GUEDES, Simone (1997). Jogo de Corpo: um estudo de construção social de trabalhadores. Niterói: EDUFF.

GUEDES, Simone (1998). O Brasil no campo de futebol. Rio de Janeiro:EDUFF.

KUPER, Adam (1978). Antropólogos e antropologia. Rio de Janeiro: Francisco Alves LOPES, José Sérgio Leite (1994). A vitória do futebol que incorporou a pelada. Revista USP: Dossiê Futebol, 22, São Paulo.

LOVISOLO, Hugo (2001). Saudoso futebol, futebol querido: a ideologia da denúncia. In: HELAL, Ronaldo, SOARES, Antônio e LOVISOLO, Hugo. A invenção do país do futebol. Rio de Janeiro: Mauad, p. 77-99.

MASCARENHAS, Gilmar (1998). Futebol e territorialidade da segregação racial em Porto Alegre. In: Motus Corpori. Vol. 5, n ${ }^{\circ}$. Rio de Janeiro, Gama Filho, 1998.

MAGNANI, J. Guilherme (1998). Festa no pedaço: cultura popular e lazer na cidade. São Paulo, Hucitec [1 ed., Brasiliense, 1984].

MAGNANI, J. Guilherme (2002). De perto e de dentro: notas para uma etnografia urbana. In: Revista Brasileira de Ciências Sociais. São Paulo, vol. 17 , n. 49.

MAGNANI, José Guilherme e MORGADO, Naira (1996). Futebol de várzea também é patrimônio. In: Revista do Patrimônio Histórico e Artístico Cultural. São Paulo, n. 24, p. 175-84.

MURRAY, Bill (2000). Uma história do Futebol. São Paulo: Hedra

PEREIRA, Leonardo (2000). Footballmania: uma história social do futebol. Rio de Janeiro: Nova Fronteira.

Movimento, Porto Alegre, v. 9, n. 2, p. 129-156, maio/agosto de 2003 
SAHLINS, Marshall (1997). O pessimismo sentimental e a experiência etnográfica: porque a cultura não é um objeto em via de extinção. Mana, 3 (1 e 2).

SAOUTER, Anne (2000). Être Rugby: jeux du masculin et du féminin. Paris: Édition de la MSH/Mission du Patromoine Ethnologique.

STIGgER, Marco Paulo (2002). Esporte, lazer e estilos de vida: um estudo etnográfico. Campinas: Autores Associados.

TOLEDO, Luiz Henrique de (2001).Futebol e teoria social: aspectos da produção científica brasileira (1982-2002). BIB, 52: 133-166, São Paulo.

TOLEDO, Luiz Henrique de (2002). Lógicas no Futebol. São Paulo: Hucitec/ FAPESP.

TUBINO, Manoel José Gomes (1992). Dimensões sociais do esporte. Sao Paulo: Cortez.

TURNER, Victor (1974a). Dramas, Fields and Metaphors: Symbolic Action in Humanan Society. Ithaca \& Londres: Cornell University Press.

TURNER, Victor (1974b). O Processo Ritual: Estrutura e Antiestrutura. Petrópolis: Vozes.

WEBER, Max (1979). Sociologia. São Paulo: Ática. 